CLINICAL ETHICS

\title{
Ideals of patient autonomy in clinical decision making: a study on the development of a scale to assess patients' and physicians' views
}

\section{A M Stiggelbout, A C Molewiik, W Otten, D R M Timmermans, J H van Bockel, J Kievit}

J Med Ethics 2004;30:268-274. doi: 10.1136/jme.2003.003095

See end of article for authors' affiliations

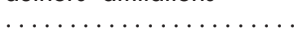

Correspondence to: Dr A M Stiggelbout Department of Medical Decision Making, Leiden University Medical Center, PO Box 9600, 2300 RC Leiden; a.m.stiggelbout@ lumc.nl

Received 13 January 2003 Revised 21 May 2003

Accepted 2 June 2003
Objectives: Evidence based patient choice seems based on a strong liberal individualist interpretation of patient autonomy; however, not all patients are in favour of such an interpretation. The authors wished to assess whether ideals of autonomy in clinical practice are more in accordance with alternative concepts of autonomy from the ethics literature. This paper describes the development of a questionnaire to assess such concepts of autonomy.

Methods: A questionnaire, based on six moral concepts from the ethics literature, was sent to aneurysm patients and their surgeons. The structure of the questionnaire was assessed by factor analysis, and item reduction was based on reliability.

Results: Ninety six patients and 58 surgeons participated. The questionnaire consisted of four scales. Two of the scales reflected the paternalistic and consumerist poles of the liberal individualist model, one scale reflected concepts of Socratic autonomy and of procedural independence, and the fourth scale reflected ideals of risk disclosure.

Discussion: The Ideal Patient Autonomy Scale is a 14 item normative instrument. It is clearly distinct from the generally used psychological preference questionnaires that assess preferences for physician-patient roles.

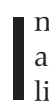
n the last two decades, the term "patient autonomy" has appeared more and more frequently in the medical literature. A textword search in PubMed provided 41 citations for 1980 and 324 for 2000. In the medical literature authors generally seem to imply the liberal individualist concept of autonomy as defined by Beauchamp and Childress, ${ }^{1}$ in which autonomous patients are choosers who act intentionally, with understanding, and without controlling influences that determine their actions. According to this interpretation of autonomy, the goal for an autonomous person is to decide on his or her own, without undue manipulation by others. In the medical subject headings $(\mathrm{MeSH})$ the term "autonomy", which is not a MeSH term, is however associated with the MeSH term "freedom" - that is, "the rights of individuals to act and make decisions without external constraints". One of the first empirical papers in medical decision making on patient autonomy ${ }^{2}$ thus linked autonomy to the question of whether patients wanted to make decisions themselves. In the descriptive medical decision making literature, this meaning has become the default. ${ }^{3}{ }^{4}$ Autonomy refers to the decision making dimension of the patient role, and enhancing patient autonomy means helping patients make their own decisions. The patient described in the informative model from the well known paper of Emanuel and Emanuel ${ }^{5}$ corresponds with an autonomous patient in this sense. In this connotation, a concomitant dimension that is often evaluated simultaneously in research on patient autonomy, is that of desire for information. ${ }^{2}{ }^{4}$ Patients who actively seek information are generally seen as more autonomous because, in the liberal individualist interpretation, information is seen as a necessary condition for autonomous choice.

In the ethics literature other connotations of the term autonomy have appeared, which are increasingly used to describe (and prescribe) medical practices. These alternative concepts of autonomy will be described in the next section. Examples are autonomy as critical reflection, as proposed by Dworkin, ${ }^{6}$ and autonomy as identification, as advocated by Agich. ${ }^{7}$ Unfortunately, the medical literature seldom refers to these concepts of autonomy, although they are potentially of great use.

Many descriptive studies in health care have assessed the prevalence of patient preferences for the liberal individualist interpretation. These studies have generally not assessed patient ideals, but have described autonomy as a psychological attribute, and have tried to scale patients on a preference questionnaire (Molewijk AC, unpublished data)-well known, for example, is the Degner Control Preferences Scale, ${ }^{8}$ assessing patients' preferences for independent decision making. From this descriptive literature it emerged that many patients do not have a strong preference for autonomy in the liberal individualist sense, and many even prefer a paternalistic model (see Benbassat ${ }^{3}$ for an overview). Such preferences seem at odds with the ideal of evidenceinformed patient choice, ${ }^{9}$ in which an autonomous patient in the liberal individualist sense decides for himself. It fits more closely with an alternative concept of autonomy, like Dworkin's above mentioned concept of critical reflection (also named procedural independence). ${ }^{6}$ According to this concept a patient may decide to leave all the decisions to the physician, in a way similar to that of religious subjects who deliver themselves to their elder.

In our research we wished to explore patients' and physicians' perceptions of autonomy while extending the concept beyond the liberal individualist ideal of independent decision making. We wished to explore these perceptions from an explicitly normative point of view-that is, to explore ideals not preferences. An ideal is based upon critical reflection on what one wants to be or how one wants to act, referring to the "good life", in line with one's norms and values. Preferences are more affective, and refer to what is most satisfactory. A patient's ideal might be to act with responsibility and make the decision him or herself. In practice this 
same patient may prefer to leave the decision to the physician, because ultimately she or he does not have the courage to decide (Molewijk, unpublished observations). As the prevailing interpretation of autonomy in the medical literature appears to be the liberal individualist one and, as in practice, patient preferences are at odds with this interpretation, we wished to assess whether patient ideals are different from their preferences or whether other views than the liberal individualist prevail in practice. Studying patient ideals, and social practices in general, is important from the perspective of integrated empirical ethics. ${ }^{10}{ }^{11}$ Integrated empirical ethics research refers to studies in which ethicists and social scientists cooperate in combining moral theory and social scientific research methods. Such studies result from the view that, in the end, there is no fundamental distinction between fact and value, and that the empirical and the normative are interconnected. On the one hand, facts produced by "descriptive" sciences are interwoven with discipline specific epistemic values-for example, the information presented to patients may partly shape a certain kind of patient autonomy. On the other hand, every moral theory is based on empirical premises. In the context of our research, different moral theories on patient autonomy assume different ideas with respect to the identity and rationality of humans. One cannot construct a normative theory on patient autonomy without referring to an interpretation of what human beings actually "are". If empirical research shows that a certain empirical premise is not feasible, then it might challenge the validity of the associated moral theory. People should not be held to a standard that they are unlikely to satisfy. ${ }^{12}$ For example, if social scientific research shows that many patients do not have the cognitive capacity to understand medical information, one may question the liberal individualist notion of patient autonomy.

Integrated empirical ethics thus does not believe in the prima facie moral authority of a social practice nor in that of a moral theory. It is concerned with the contextual relevance of moral theory for the morality of specific social practices and vice versa (that is, morality derives its meaning from the context). A goal of using empirical data may be the improvement of existing moral theories. For example, one might wish to modify the theory of patient autonomy towards the social practice of surgical decision making in elderly men on the basis of empirical data.

To assess the moral beliefs within the practice of surgical decision making, we wished to develop a scale that assesses patients' and clinicians' ideals of autonomy, not their preferences, and that links these ideals to elements from the most important prevailing ethical theories (to be described in the next section). A somewhat similar attempt at eliciting idealslimited to surgeons, not patients-has been described by Falkum and Førde, ${ }^{13}$ who restricted their assessment to the central dimensions of three of the four well known models of the physician-patient relationship of Emanuel and Emanuel ${ }^{5}$ (the paternalistic, the informative, and the deliberative* ${ }^{*}$. A scale that on first examination seems to have a somewhat similar normative objective is the Patient-Practitioner Orientation Scale developed by Krupat et al. ${ }^{14}$ In this scale, the items are framed in a normative sense ("the doctor should..."), but nevertheless it is aimed at assessing patient centred versus disease centred preferences, and solely from a patient perspective. We explicitly wished to assess these views both in clinicians and in their patients, because it is in their interaction that decisions are made. In any physician-patient relation, whether paternalistic or other, both parties play a role and the views of both are therefore relevant.

* The authors viewed the fourth model -the interpretive model-to have limited relevance for medical consultations as compared (for example) with psychotherapy.
The study presented here was performed in the context of a large research project on decision support and patient autonomy in surgical decision making. Our study has an explorative character. We did not start from one normative point of view, nor was our ultimate goal to quantify the prevalence of the support for the various theories. We wished to assess whether aspects of ethical theories other than liberal individualism can be distinguished in medical practice. As preferences for information have been found to be the second major dimension of patient autonomy in the descriptive literature, we were interested in the role of risk information in different concepts of patient autonomy. Information may be perceived as necessary for autonomous decision making, but at the same time its sometimes complex and threatening nature may obstruct autonomous decision making if patients feel overwhelmed by the information.

This paper describes our attempt at developing and testing a questionnaire to assess patients' and surgeons' ideals of autonomy. It describes the item selection, the factor structure, and internal consistency of the scale. It presents the validity checks we performed: assessing correlations among the subscales of the instrument, and comparing scores on the instrument with a question on patients preferences for participation in treatment decisions that is often used in decision making research. ${ }^{15}$ As some of the items covered in our questionnaire pertain to the decision making role, we expected our questionnaire to correlate with this question, but the correlation was not expected to be very high, given the more normative perspective that we held.

\section{METHODS}

The construction of the Ideal Patient Autonomy Scale The starting point for the construction of the questionnaire was the following six moral concepts of patient autonomy from the ethics literature (Molewijk AC, unpublished data).

- The liberal legal concept of respect for autonomy, based on Berlin's negative concept of freedom, ${ }^{16}$ which stresses "freedom from" interference by others. It protects vulnerable patients from unwanted interference by physicians by demanding respect for a patient's integrity. It is thus directed towards those who treat or care for the patient, not to the patient himself.

- The liberal individualist concept of autonomy as defined by Beauchamp and Childress, ${ }^{1}$ who define autonomous patients as choosers who act intentionally, with understanding, and without controlling influences that determine their actions. It thus assumes that patients are rational and reasonable agents. Proponents of this concept of autonomy believe that a physician's obligation to respect autonomy outweighs, to a certain degree, professional obligations of beneficence.

- Autonomy as critical reflection, within the theory of procedural independence, ${ }^{6}$ is normative in its criteria for the process of autonomous decision making. If the criteria of procedural independence are satisfied, this approach offers room for conscious submission to some form of external authority (for example, a physician, a religion, a leader, etc). In this concept, the paternalistic physician can play a role. Central to this concept is the critical reflection on decisions. After critical reflection on their preferences, patients may choose to let the physician decide which treatment is best.

- Actual autonomy as identification, ${ }^{7}$ which refers to the process of identification with one's actions. It originated in phenomenological approaches to health care, in which identification refers to judging experiences in the light of one's value orientation towards actions. It is important in this interpretation for a patient to identify him or herself 
with the decision made, not so much to make the decision him or herself. Identity refers not so much to identity as an independent being, but to identity as a social being influenced by emotions and by ties with others. Dependence is not problematic if one can identify with the source upon which or whom one is dependent.

- Socratic autonomy, which stresses the importance of caring, and thus links the concept of autonomy with existential fragility and patients' vulnerability. The core is not an ethics of personal responsibility and self determination, but an ethics of care and of interdependence. ${ }^{17}{ }^{18}$

- Autonomy as negotiated consent ${ }^{19}$ refers to interpersonal and social communication, instead of individual and rational considerations. Communication should be understood as a process of negotiation in which people try to define the meaning of the situation in which they are involved. Patients and physicians should have an intention to mutual understanding and to explicit and just communication. Perhaps this theory best fits many of the ideas on shared decision making that have evolved in recent years. ${ }^{20}$

Using the theories, we developed 55 initial statements to be answered on a 5 point scale (ranging from "fully disagree" to "fully agree"). As stated in the introduction, we were also interested in the specific role of risk information, because information is consistently associated with autonomy in the literature. Further, risk information forms an important component of our decision support. In some of the moral concepts it is not evident what the role of information would be in the ideal of autonomy. Therefore the items that pertain to risk information are not clearly linked to the autonomy concepts. The statements were piloted in three samples: in students of high level vocational training in medicine; in general practitioners during a course in continuing medical education; and in aneurysm patients. In this pilot, we had tried to represent each theory with a similar number of items. Because of lack in variance of some of these items, we decided to limit the questionnaire to items showing sufficient variance. Further, the original set of statements included items that did not discriminate well between the theories, as the theories in some respects show overlap. Following the pilot we therefore decided to use the different elements from the theories merely to obtain a wide range of possible views of the ideal of autonomy that patients and doctors may hold. Thus, our aim was not to develop subscales that exactly represent moral theories, but subscales that may result in a "normative map" of possible patient-physician relationships, based on these theories. The proposed future use for the questionnaire is to compare patients' and surgeons' positions on such a normative map (Molewijk, unpublished observations), and therefore the questionnaire was developed for and evaluated in both groups. On the basis of the responses to this questionnaire and psychometric analyses thereof, a final list of 22 statements was created (see Appendix 1). Two versions of the instructions were created: a patient version and a physician version. In both versions, the respondents were asked what they thought constituted a good patient-physician relationship, based on their norms and values. $†$ It was explicitly stated that they should not indicate what had been their experience so far, or what they thought would be feasible or most commonly encountered. The surgeons were addressed as physicians-they were not asked to imagine being patients.

† In our pilot study, we had used the term "your ideal of the patientphysician relation", but this turned out to be too abstract for the patients. After thorough discussion we decided to use the term "good relation" instead, with the qualifications as given above (Molewijk AC, unpublished data).
Included as a validity check (as the final item of the questionnaire) was a question on the patient's preference for participation in treatment decision making, which was developed by Sutherland. ${ }^{15}$ This item asks for the patient's preferred decision making role on a 5 point scale.

\section{Participants}

The questionnaire was tested in two samples: a sample of aneurysm patients and a sample of surgeons and surgical residents. The patients were participants in a randomised trial on the effect of individualised evidence based decision support on the decision making about elective aneurysm surgery. Patients were recruited from the Leiden University Medical Center, and from the Westeinde and the Leyenburg Hospitals in The Hague, all in the West of the Netherlands. Patients received the questionnaire by mail around the time of their first appointment with the vascular surgeon. A prepaid envelope was sent for returning the filled out questionnaire. The study was approved by the research ethics committees of all three hospitals.

The surgeons were those participating in the larger research project, as well as surgical residents from the same region (between years 1 and 6 of their training). The surgeons and residents were also sent the questionnaire with a prepaid return envelope.

\section{Data analysis}

A global overview of the data analysis is presented here. For technical details, the reader is referred to Appendix 2. The first step in item reduction was based on extremeness of scores. Items that most respondents agree with are not very informative and were therefore omitted. Next, a factor analysis was carried out on the reduced questionnaire to see whether subscales (factors) could be formed that were related in some way to the autonomy concepts. The factors thus found were submitted to a second round of item reduction. We eliminated items within each factor (subscale) separately, in a stepwise fashion, based on Cronbach's $\alpha$, a measure of internal consistency. ${ }^{21}$ In this process of deleting redundant items the item reduction was not based purely on statistical grounds-the content of the items was also taken into account. In this way we tried to create a short questionnaire that covered the relevant domains. We analysed data for patients and clinicians together, but we also assessed factor structure and reliability for the two groups separately to see whether differences were observed. In deciding to delete an item or not we also took the internal consistency in the two subgroups into account. Summary scale scores were calculated by summing the item scores (without weighting) and transforming these to a 0-100 scale. Association with the Sutherland question was assessed by correlations and oneway analysis of variance.

\section{RESULTS}

\section{Participants}

A total of 160 patients were eligible for the randomised trial: $17(11 \%)$ of whom refused to participate (in the trial). Of the 143 patients thus available for this substudy, 23 (16\%) did not return their questionnaire whereas 18 (15\%) of the returned questionnaires were unusable because the autonomy questionnaire had not been filled in. Of the remaining 102 patients $(71 \%)$, one patient who had missing values for more than $25 \%$ of the 22 items was omitted from the analysis. Five patients who agreed fully $($ score $=5$ ) to 20 $(90 \%)$ or more of the items were omitted from the analyses. This left us with 96 patients available for analysis. Mean age was 72 (SD 8 ) years, 90\% were male, and $44 \%$ had lower, $40 \%$ intermediate, and $16 \%$ higher education. Fifty eight of the 71 surgeons and residents approached replied (82\%). 
Table 1 Factor structure after exploratory factor analysis $(n=144)^{*}$

If
20. The doctor can presume that the patient knows that people
can die during serious operations.
16. If doctor and patient cannot agree on which treatment is
best, the doctor should make the final decision.
18. The patient should, without much information on the risk
involved, confidently undergo an operation.
12. During the conversation, the patient must submit himself with
confidence to the expertise of the doctor.
4. It is better that the doctor rather than the patient decides which
the best treatment is.
1. The doctor must choose the treatment with the least health risk,
even when the patient wants a treatment with more health risks.
8. Every patient is obliged to actively think about the appropriate
treatment.
22. As it concerns the body and life of the patient, the patient
should decide.
13. The patient himself must choose between the various treatments.
19. It goes too far when the doctor decides which treatment is best
for the patient.
21. If a patient chooses a treatment with more health risks, the
doctor should respect this treatment decision.
10. It goes too far when patients themselves have to decide which
treatment is best for them.
11. Patients should have the right not to be involved in the decision
on the treatment.
15. Patients who become afraid when thinking about the treatment
decision should be left in peace by the doctor.
3. If the patient does not want to receive information about risks
the doctor should respect this.
14. Before a patient consents to a treatment he should receive all
information on the risks involved.
5. The patient has to be informed on all the risks involved in an
operation.
* Only factor loadings greater than 0.3 are displayed.

\section{Item reduction}

The first criterion for item reduction applied was extremity of mean score. We deleted four items $(2,6,9,17)$ because they had a mean of greater than 4.5 and standard deviation of less than 1.0. In the subsequent factor analysis, four factors were found (see table 1; see Appendix 2 for details of the statistical analysis). Item reduction based on internal consistency produced 4 scales (see table 2 ). The first, and most reliable factor $(\alpha=0.83)$, was found to be a factor describing the opinion that the physician should decide and reflected a relationship based on trust. We will refer to this factor as the "doctor knows best" factor. Item I ("The doctor must choose the treatment with the least health risk, even when the patient wants a treatment with more health risks") also loaded on this factor, but eliminating this item did not reduce reliability overall, and improved the reliability for surgeons. Item 8 ("Every patient is obliged to actively think about the appropriate treatment") loaded most strongly on this factor, but the factor loading was only moderate (0.41) and not much higher than the item's loading on the other three factors. Further, inclusion of this item reduced internal consistency and was therefore decided against. The second factor $(\alpha=0.62)$ reflected the view that the patient should decide. The third factor $(\alpha=0.66)$ described the view that a patient is entitled to the wish not to participate, and to the wish not to receive threatening information. The fourth factor consisted of two items (items 5 and 14) that reflect requirements for risk information $(\alpha=0.63)$. The four factors explained $19 \%, 13 \%$, $11 \%$, and $11 \%$, respectively, of the variance after rotation.

An item that we would have preferred to retain is item 7: "If doctor and patient properly consult with each other, it does not matter who makes the final decision". It did not clearly fit with any of the scales, but concerned an important concept from the ethics literature. We had felt it to reflect both the theory of negotiated consent and that of actual identification. In the factor analysis it was originally grouped with item 10 (which we hoped would reflect procedural independence/critical reflection and Socratic autonomy), and when forcing four factors it was grouped with items 5 and 14 (the more legal aspects of information provision). For both of these combinations, reliability was inadequate when the item was included. Other items that were expected to correlate with this item (that were meant to reflect negotiated consent or identification-see Appendix 1) were items that had been endorsed by almost everyone, and had been deleted in the first round of item reduction-for example, items 2 and 17). In questionnaire development it is not recommended to keep a single item (for reasons of reliability) and therefore it was deleted.

As we were concerned about the positive answering tendency among patients, we tested the impact of agreement. We assessed how many participants fully agreed with four pairs of items that we felt were unlikely to elicit full agreement in both instances in a pair (items 1 and 21 , items 8 and 11 , items 8 and 15, and items 10 and 13). Though strictly speaking these items are not opposites of a scale, we felt that agreeing to both items in a pair indicated acquiescence bias.22 Five surgeons had fully agreed with both items in one pair only, and 20, 17, and nine patients had fully agreed with both items in one, two, and three pairs, respectively. A factor analysis without the 26 patients who had agreed to two or more of the above pairs resulted in a similar structure and similar reliabilities, except for a reduced reliability in patients for the non-participation factor, from 0.59 to 0.52 .

\section{Correlation among scales}

A positive correlation was seen between the "doctor knows best" scale on the one hand, and both the "right to nonparticipation" scale and the "obligatory risk information" 
Table 2 The four subscales of the Ideal Patient Autonomy Scale (IPAS) Scale I Doctor knows best: $\alpha=0.83$ (surgeons: $\alpha=0.59$; patients:
$\alpha=0.70$ )

16. If doctor and patient cannot agree on which treatment is best, the doctor should make the treatment decision.

4. It is better that the doctor rather than the patient decides which is the best treatment.

12. During the conversation, the patient must submit himself with confidence to the expertise of the doctor.

20. The doctor can presume that the patient knows that people can die during serious operations.

18. The patient should, without much information on the risk involved, confidently undergo an operation.

Scale II Patient should decide: $\alpha=0.62$ (surgeons: $\alpha=0.62$; patients: $\alpha=0.63$ )

13. The patient himself must choose between the various treatments.

21. If a patient chooses a treatment with more health risks, the doctor should respect this treatment decision.

19. It goes too far when the doctor decides which treatment is best for the patient.

22. As it concerns the body and life of the patient, the patient should decide.

Scale III Right to non-participation: $\alpha=0.66$ (surgeons: $\alpha=0.57$; patients: $\alpha=0.59$ )

3. If the patient does not want to receive information about risks, the doctor should respect this.

15. Patients who become afraid when thinking about the treatment decision should be left in peace by the doctor.

11. Patients should have the right not to be involved in the decision on the treatment.

Scale IV Obligatory risk information: $\alpha=0.63$ (surgeons: $\alpha=0.54$;

patients: $\alpha=0.54$ )

5. The patient has to be informed on all the risks involved in an operation.

14. Before a patient consents to a treatment he should receive all information on the risks involved.

scale on the other (see table 3). A positive correlation was also seen between the "patient should decide" scale and the "right to non-participation" scale. The correlation between the "obligatory risk information" scale and the "right to nonparticipation" scale was only moderate.

\section{Association with the Sutherland question}

As the distribution of the Sutherland question was skewed (see table 4), we assessed the association with the scales not only by correlations but also by means of one way analysis of variance using the test for linear trend. The associations with the four scales were as expected (see tables 3 and 4). The "right to non-participation" scale and the "obligatory risk information" scale were not linearly associated with the item. The "patient should decide" scale most clearly showed the expected association $(r=0.45, \mathrm{p}<0.01)$, but the "doctor knows best" scale also showed a (negative) association $(r=-0.22, \mathrm{p}<0.05)$. Indeed, in the Analysis of Variance (ANOVA) a linear trend was seen for these two scales.

Table 3 Correlation among scales (Pearson's $r$ ), $n=144$

\begin{tabular}{lcccc}
\hline & DKB & PatD & nonP & RI \\
\hline Doctor knows best (DKB) & & & & \\
Patient should decide (PatD) & -0.09 & & & \\
Right to non-participation (nonP) & $0.43^{*}$ & $0.24^{*}$ & & \\
Obligatory risk information (RI) & $0.31^{*}$ & 0.12 & $0.20 \dagger$ & \\
\hline Sutherland item & $-0.22^{*}$ & $0.45^{*}$ & -0.03 & 0.02 \\
\hline${ }^{*} \mathrm{p}<0.01$ (two sided); $\dagger \mathrm{p}<0.05$ (two sided). & & & \\
\hline
\end{tabular}

\section{DISCUSSION}

We developed the Ideal Patient Autonomy Scale to assess ideals of patient autonomy from a broader perspective than that of liberal individualism alone. Based on factor analysis and reliability analyses, the original questionnaire of 22 items was reduced to 14 items that formed four scales with moderate to good reliability. By incorporating aspects from various ethical theories a subtler picture of the physicianpatient role emerges than is generally suggested by the medical literature. Two of the four factors reflect the well known distinction between physician-centred and patientcentred decision making. The third is a subtle, but important aspect of the patient-physician relationship, namely the right of the patient to decide whether to delegate the decision back to the physician. The fourth reflects the right and the duty of patients to be made aware of relevant risks.

When we compare the factor structure with our original classification of the items according to ethical theories, a remark should be made. In the pilot study we had abandoned the idea that we could cover all theories with equal numbers of statements. The original set of statements included many items that did not discriminate between theories, and several items showed no variation between respondents. Thus, we do not pretend that our original set of items reflected the theories in a balanced way.

A limitation of our study is the selective sample of patients. The mean age of our population was high and the level of education was low. Patients were self selected in that they were willing to participate in our trial, but as only $11 \%$ refused participation this will not have introduced a large bias. Just over $30 \%$, however, did not return the questionnaire or did not fill out the Ideal Patient Autonomy Scale. Further testing in other patient populations is thus needed.

A factor that corresponded closely to our preconceived ideas about alternative autonomy concepts was the "right to non-participation" factor. All three items reflected to some extent the concept of procedural independence, and two could also be referred to as to Socratic autonomy (see Appendix 1). This factor may be seen as the counterpart of the ideal patient in the liberal individualist sense: the view that a patient is entitled to not participate and to not receive information that causes fear. The "doctor knows best" factor encompasses some of the items that we had classified beforehand as Socratic autonomy or as procedural independence. They thereby strongly incorporate the concept of trust-an important value in medicine..$^{23}$ The "patient should decide" factor corresponded quite well with our concepts: all four items had been classified beforehand as (to some extent) liberal individualist, even though one item (number 22) could also be seen as "identification". The "doctor knows best" scale and the "patient should decide" scale emerged as two distinct factors that seem to represent the opposites of a continuum. Forcing the two factors into one did reduce the reliability to 0.71 , and subsequent stepwise elimination of items led to the original doctor knows best scale (with $\alpha$ of 0.83 ). Thus, the "patient should decide" scale reflects a distinct concept, which is in accordance with our expectations as discussed above. The "obligatory risk information factor", finally, consisted of two items that we had both classified a priori as "liberal juridical".

Four items were deleted because almost all participants agreed with them; they stated the obvious. Three items $(1,8$, and 10) could be deleted from the scales to improve reliability as their content was sufficiently covered by other items in the questionnaire. An item we deleted from the analysis for reasons of reliability is item 7: "If doctor and patient properly consult with each other, it does not matter who makes the final decision". We had felt that it reflected both the theory of negotiated consent and that of actual identification. Others who 
Table 4 Mean (standard deviation) scale scores by level of the Sutherland question $(n=144)$

\begin{tabular}{|c|c|c|c|c|c|}
\hline & $\mathbf{N}(\%)$ & $\begin{array}{l}\text { Doctor knows } \\
\text { best }^{*}\end{array}$ & $\begin{array}{l}\text { Patient should } \\
\text { decide } †\end{array}$ & $\begin{array}{l}\text { Right to non- } \\
\text { participationf }\end{array}$ & $\begin{array}{l}\text { Obligatory risk } \\
\text { information }\end{array}$ \\
\hline $\begin{array}{l}\text { Physician should decide, based } \\
\text { on all that is known }\end{array}$ & 13 & $84.6(17.4)$ & $20.2(16.8)$ & 74.4 (24.2) & $87.5(16.1)$ \\
\hline $\begin{array}{l}\text { Physician should decide, } \\
\text { strongly taking the patient's } \\
\text { opinion into account }\end{array}$ & 55 & $55.9(30.2)$ & $43.4(24.1)$ & $51.5(28.1)$ & $79.8(23.0)$ \\
\hline $\begin{array}{l}\text { Physician and patient should } \\
\text { decide together, on basis of } \\
\text { equity }\end{array}$ & 50 & $63.3(29.9)$ & $58.8(19.6)$ & $62.7(29.3)$ & $82.8(26.1)$ \\
\hline $\begin{array}{l}\text { Patient should decide, strongly } \\
\text { taking the physician's opinion } \\
\text { into account }\end{array}$ & 19 & $46.8(30.4)$ & $62.8(21.3)$ & $61.0(29.9)$ & $88.2(16.4)$ \\
\hline $\begin{array}{l}\text { Patient should decide, based on } \\
\text { all that he or she knows or hears } \\
\text { about the treatments }\end{array}$ & 7 & $43.6(31.2)$ & $60.7(20.0)$ & $47.6(26.2)$ & $78.6(22.5)$ \\
\hline
\end{tabular}

*Significant difference between levels $(p=0.003)$ and linear trend $(p=0.008)$.

$\dagger$ Significant difference between levels $(p<0.001)$ and linear trend $(p<0.001)$.

$\ddagger$ Significant difference between levels $(p=0.05)$.

would like to use the questionnaire, and who value the mentioned concepts (Molewijk AC, unpublished data), should consider keeping this item and adding similar items to form a reliable scale.

The positive correlation between the "doctor knows best" scale and the "right to non-participation" scale was in the expected direction. The positive correlation between the "physician decides" scale and the "obligatory risk information" scale confirms the findings in the literature that information provision and decision making are distinct concepts, and that the physician who decides for the patients should still fulfil all requirements regarding risk disclosure. The positive correlation between the "patient should decide" scale and the "right to non-participation" scale may be explained by the fact that both scales encompass items stating that the patient's word is law. This correlation may also indicate that those who believe that a patient should decide also believe that in certain situations the patient may decide to delegate his or her decision to the physician-a view that is reflected among others in the theory of procedural independence. These hypotheses deserve further exploration.

Our final questionnaire consists of 14 items, which form the scales presented in table 2 . As stated above, item 7 could well be retained but similar items should then preferably be added to create a reliable scale. Three of the scales have an $\alpha$ of less than 0.70, which is less than ideal. But given the early stages of our validation research, the highly abstract nature of the concepts that we wish to assess, and the fact that our patients had generally low education levels (and therefore may have had difficulty understanding the items, which may have reduced the internal consistency of the responses), we believe it to be acceptable. It will be worth the time and effort to increase the number of items and reduce measurement error in other ways. Further, reverse scoring of some of the items should reduce acquiescence. Most correlations among scales, and between the scales and the Sutherland question, supported the validity of the scale. We do not know whether the factor structure that we found can be reproduced in other cultures, because ideals of autonomy do not only differ by culture, but perceptions of aspects as normatively inherent to autonomy may also be different. We therefore urge others to adapt and use this scale and to present psychometric analyses to obtain more insight into this complicated but highly interesting concept. The scale can then be used to compare populations with respect to their views on autonomy, and to assess what patient or physician characteristics are correlated with certain ideal types. As stated in the introduction, we believe that social practice should be used as a moral source as morality derives its meaning from the context. Use of our questionnaire may enrich the current debates on the ethical aspects of evidence based patient choice ${ }^{9}$ and shared decision making. ${ }^{20}{ }^{24}$ In our study, support was clearly found for other concepts of autonomy than the liberal individualist, such as that of procedural independence. This concept does not fit very well the paradigm of evidence based patient choice. Thus, more insight into the views on autonomy that are found in practice may on the one hand help sharpen ethical theory. On the other hand, it may point to beliefs and attitudes in practice that are less ideal, from a normative viewpoint, and need modification.

\section{Authors' affiliations}

A M Stiggelbout, A C Molewijk, W Otten, J Kievit, Department of Medical Decision Making, of the Leiden University Medical Center, Leiden, The Netherlands

J H van Bockel, Department of Surgery of the Leiden University Medical Center, Leiden, The Netherlands

D R M Timmermans, Department of Social Medicine of the Free University Medical Center, Amsterdam, The Netherlands

Supported by a grant of the Netherlands Council for Scientific Research NWO.

\section{APPENDIX 1 ORIGINAL PATIENT AUTONOMY QUESTIONNAIRE}

See next page.

\section{APPENDIX 2 DETAILS OF THE STATISTICAL ANALYSES}

In the initial exploratory factor analysis, five factors were found after varimax rotation, with eigenvalues greater than 1.0, of which the last two each consisted of two items only (items 5 and 14, and items 7 and 10, respectively). Because the latter factor had very poor reliability $(\alpha=0.27)$, and as the factors 5 to 18 lay more or less on a straight line on the scree plot (which separates important early factors from random error in the later factors, and usually results in fewer factors than a solution based on eigenvalues), we forced the procedure to extract four factors (see table 1). We performed an additional factor analysis to assess the impact of the decision to delete the four items with extreme scores. The same factor structure emerged, and in a subsequent reliability analysis the four items were deleted anyway. 


\begin{tabular}{|c|c|c|}
\hline Normative statement & $\begin{array}{l}\text { Autonomy } \\
\text { concept }^{*}\end{array}$ & $\begin{array}{l}\text { Retained in final } \\
\text { questionnaire }\end{array}$ \\
\hline $\begin{array}{l}\text { 1. The doctor must choose the treatment with the least health risk, even } \\
\text { when the patient wants a treatment with more health risks. }\end{array}$ & $\sqcup$ & No \\
\hline 2. It is good if the patients asks the doctor critical questions. & LI, NC & No \\
\hline $\begin{array}{l}\text { 3. If the patient does not want to receive information about risks, the doctor } \\
\text { should respect this. }\end{array}$ & LI, NC & Yes \\
\hline $\begin{array}{l}\text { 4. It is better that the doctor rather than the patient decides which the best } \\
\text { treatment is. }\end{array}$ & U, SA, PI & Yes \\
\hline 5. The patient has to be informed on all the risks involved in an operation. & U, LI & Yes \\
\hline $\begin{array}{l}\text { 6. The doctor should not only pay attention to the medical aspects; he or } \\
\text { she should also pay attention to the personal experiences of the patient. }\end{array}$ & I, SA & No \\
\hline $\begin{array}{l}\text { 7. If doctor and patient properly consult with each other, it does not matter } \\
\text { who takes the final decision. }\end{array}$ & $\mathrm{NC}, \mathrm{I}, \mathrm{SA}, \mathrm{PI}$ & See Discussion \\
\hline 8. Every patient is obliged to actively think about the appropriate treatment. & LI, NC, I & No \\
\hline 9. If patients do not understand something they should tell their doctor this. & $\mathrm{NC}, \mathrm{PI}$ & No \\
\hline $\begin{array}{l}\text { 10. It goes too far when patients themselves have to decide which } \\
\text { treatment is best for them. }\end{array}$ & $\mathrm{PI}, \mathrm{SA}$ & No \\
\hline $\begin{array}{l}\text { 11. Patients should have the right not to be involved in the decision on the } \\
\text { treatment. }\end{array}$ & $\mathrm{PI}, \mathrm{SA}$ & Yes \\
\hline $\begin{array}{l}\text { 12. During the conversation, the patient must submit himself with } \\
\text { confidence to the expertise of the doctor. }\end{array}$ & $\mathrm{PI}, \mathrm{SA}$ & Yes \\
\hline 13. The patient himself must choose between the various treatments. & LI & Yes \\
\hline $\begin{array}{l}\text { 14. Before a patient consents to a treatment he should receive all } \\
\text { information on the risks involved. }\end{array}$ & $\sqcup$ & Yes \\
\hline $\begin{array}{l}\text { 15. Patients who become afraid when thinking about the treatment decision } \\
\text { should be left in peace by the doctor. }\end{array}$ & SA, PI & Yes \\
\hline $\begin{array}{l}\text { 16. If doctor and patient cannot agree on which treatment is best, the } \\
\text { doctor should take the final decision. }\end{array}$ & U, LI & Yes \\
\hline $\begin{array}{l}\text { 17. Before the decision on the appropriate treatment is taken, the goals } \\
\text { and wishes of the patient must be clearly known. }\end{array}$ & NC, SA, I & No \\
\hline $\begin{array}{l}\text { 18. The patient should, without much information on the risk involved, } \\
\text { confidently undergo an operation. }\end{array}$ & $\mathrm{PI}, \mathrm{SA}$ & Yes \\
\hline $\begin{array}{l}\text { 19. It goes too far when the doctor decides which treatment is best for } \\
\text { the patient. }\end{array}$ & LI, ᄂ & Yes \\
\hline $\begin{array}{l}\text { 20. The doctor can presume that the patient knows that people can die } \\
\text { during serious operations. }\end{array}$ & $\sqcup, \mathrm{PI}$ & Yes \\
\hline $\begin{array}{l}\text { 21. If a patient chooses a treatment with more health risks, the doctor } \\
\text { should respect this treatment decision. }\end{array}$ & LI, L & Yes \\
\hline 22. As it concerns the body and life of the patient, the patient should decide. & LI, I & Yes \\
\hline
\end{tabular}

The resulting summary scale scores are obtained by summing the item scores (without weighting) and transforming these to a $0-100$ scale as follows: summary score $=(100 \times$ (scale score-minimum score)/(maximum score-minimum score)).

\section{REFERENCES}

Beauchamp TL, Childress JF. Principles of biomedical ethics. New York, Oxford: Oxford University Press, 1994.

2 Ende J, Kazis L, Ash A, et al. Measuring patients' desire for autonomy: decision making and information-seeking preferences among medical patients. J Gen Intern Med 1989:4:23-30.

3 Benbassat J, Pilpel D, Tidhar M. Patients' preferences for participation in clinical decision-making: a review of published surveys. Behav Med 1998;24:81-8.

4 Nease RF Jr, Brooks WB. Patient desire for information and decision-making in health care decisions: the Autonomy Preference Index and the Health Opinion Survey. J Gen Intern Med 1995; 10:593-600.

5 Emanuel EJ, Emanuel LL. Four models of the physician-patient relationship. JAMA 1992:267:2221-6.

6 Dworkin G. The theory and practice of autonomy. New York: Cambridge University Press, 1988.

7 Agich GJ. Reassessing autonomy in long-term care. Hastings Center Report 1990;20:12-17.

8 Degner LF, Sloan JA, Venkatesh P. The Control Preferences Scale. Can J Nurs Res 1997;29:21-43.

9 Entwistle VA, Sheldon TA, Sowden A, et al. Evidence-informed patient choice. Practical issues of involving patients in decisions about health care technologies. Int J Technol Assess Health Care 1998;14:212.

10 Molewijk AC, Stiggelbout AM, Otten W, et al. Implicit normativity in evidence-based medicine. A plea for integrated empirical ethics research. Health Care Analysis 2003;11:69-92.
11 Molewijk AC, Stiggelbout AM, Otten W, et al. Empirical data and moral theory. A plea for integrated empirical ethics. Medicine, Health Care and Philosophy. A European Journal 2004;7 (in press).

12 Weaver GR, Trevino LK. Normative and empirical business ethics: separation, marriage of convenience, or marriage of necessity? Business Ethics Quarterly 1994;4:129-43.

13 Falkum E, Førde R. Paternalism, patient autonomy, and moral deliberation in the physician-patient relationship. Attitudes among Norwegian physicians. Soc Sci Med 2001;52:239-48.

14 Krupat E, Yeager CM, Putnam S. Patient role orientations, doctor-patient fit, and visit satisfaction. Psychology and Health 2000;15: 707-19.

15 Sutherland HJ, Llewellyn-Thomas HA, Lockwood GA, et al. Cancer patients: their desire for information and participation in treatment decisions. J $R$ Soc Med 1989;82:260-3

16 Berlin I. Four essays on liberty. New York: Oxford University Press, 1969.

17 Foucault M. De zorg voor zichzelf. (Le souci de Soi) Geschiedenis van de sexualiteit. Deel 3. Niimegen: SUN, 1985.

18 Manschot H. Kwetsbare autonomie: Over afhankelijkheid en onafhankelijkheid in de ethiek van de zorg. [Vulnerable autonomy: On dependence and independence in the ethics of care]. In: Manschot $\mathrm{H}$, Verkerk M eds. Ethiek van de zorg: Een discussie [Ethics of care: a discussion]. Amsterdam: Boom, 1994:97-118.

19 Moody HR. Ethics in an aging society. Baltimore/London: The Johns Hopkins University Press, 1992

20 Charles C, Gafni A, Whelan T. Decision-making in the physician-patient encounter: revisiting the shared treatment decision-making model. Soc Sci Med 1999;49:651-61.

21 Bland JM. Altman DG. Cronbach's alpha. BMJ 1997;314:572.

22 Krosnick JA. Survey research. Annu Rev Psychol 1999;50:537-67.

23 Smith R. Medicine's core values. BMJ 1994;309:1247-8.

24 Coulter A. Partnerships with patients: the pros and cons of shared clinical decision-making. J Health Serv Res Policy 1997;2:112-21. 